\title{
A Contrastive Analysis on the Theme of Revenge in the Count of Monte Cristo and Nirvana in Fire
}

\author{
Xiaochun Luo \\ College of Foreign Language \\ Wuhan University of Science and Technology \\ Wuhan, China
}

\begin{abstract}
Dumas, a famous French writer, has a representative work called The Count of Monte Cristo Entrusted by the captain, the protagonist named Edmond, sent a letter to Napoleonic party. However, he was framed by two despicable people and the grand justice. The work tells Edmond's miserable suffering and his successful revenge years later. With vivid as well as ingeniously conceived plots and strongly artistic appeal, this work had produced a profound influence in the development of western revenge literature. While Nirvana in Fire, the adapted work of the same network novel written by Haiyan, mainly tells the overturns of injustices, the support for wise emperor, and revitalization of nation. Mei Changsu, the most intelligent person in that era, got his revenge by contending with disloyal ministers. With the booming population of this TV series, many people assume that Nirvana in Fire was the Chinese version of The Count of Monte Cristo. This paper tries to analyze the similarities and difference by comparing the two works. Furthermore, it tries to get the deep reasons for the similarities and differences.
\end{abstract} Cristo

Keywords-revenge; Nirvana in Fire; The Count of Monte

\section{INTRODUCTION}

Dumas is one of the best popular historical novelists in French and The count of Monte Cristo was his representative work. It was primarily concerned with the theme of justice, revenge, mercy and forgiveness. And it was told in the style of an adventure story. Nirvana in Fire was based on an internet novel by author Hai Yan, who was invited to pen the screenplay for the television adaptation. The story revolves around a gifted young man named Lin Shu, whose father served as a general in the army. Unfortunately, his father's army was framed, and his life totally changed. All the people died but Lin Shu survived. 12 years later, Lin Shu got his revenge and avenges the injustices dealt to his troops. The Count of Monte Cristo and Nirvana in Fire share lots of similarities and difference. The paper tries to figure out the similarities and difference between Chinese and Western revenge literature and discuss the deep reasons.

The paper is comprised of 6 indispensable parts. The first two chapter is the introduction part presenting readers the brief literature background of revenge, The Count of Monte Cristo,and Nirvana in Fire. The next two parts reveal the similarities and difference between the two works. The fifth part has a discussion upon similarities and difference in revenge. Finally comes the conclusion part, which summarizes the whole paper.

\section{LITERATURE BACKGROUND}

\section{A. A General Review upon Revenge Literature}

Revenge is a history and culture phenomenon which has been being rife in different nations. And it is an action of getting revenge on the people who have hurt their benefits and feeling. And revenge literature can be seen as general terms of any style of literature which has related description of revenge. There is a characteristic motif of revenge in the nation literature under different culture background.

Revenge literature has a long and profound history, and it is an important part of Chinese ancient literature. The preQin classics spring and autumn Biography Gong Yang recorded $\mathrm{Wu}$ Zixu's revenge deeds. And west revenge literature originally produced in Europe ancient literature, which was based on ancient Greek mythology, such as Homeric characters. During the renaissance, the development of humanism prompted the emergence of revenge literature.

Since there are differences upon traditional custom, social regulations and legal ethics, the Chinese literature was not fully identical with Western literature of the theme of revenge. Nirvana in Fire was the representative work of Chinese revenge literature, and The Count of Monte Cristo was the representative work of Western revenge literature. By comparing these two works, the common similarities and difference can be fully revealed, and the deep reasons behind similarities and difference can be seen.

\section{B. A Brief Introduction to the Count of Monte Cristo}

Edmond was a kind, innocent, honest and loving man. He honored his superiors, cared dutifully for his aging father and treated his fellow man generously. He was about to become the captain and he was engaged to a beautifully girl. But the perfect life was stir up jealousy among others. Those three people, Danglars, Fernand Mondego,and Caderousse, drafted a letter accusing Edmond of treason. And the deputy public prosecutor Villefort to send Edmond to prison for life. In prison, he knew Faria, an Italian priest and intellectual. He learned languages from Fraia and Fraia told him how to dig 
his way out. After he flees from the prison, he also found the huge treasure that Fraia left for him. He came back to Marseilles to know the details of the plot to frame him and he got the damning knowledge about them over the past decade. Ten years later, he came to Rome to get his revenge on these three people. At last, Morcerf committed suicide. Believing that everyone he loved is dead and knew that he would soon have to severe criminal charges. Villefort went insane and even Edmond spared Danglar's life but left him penniless. He was giving his enemy the chance to repent and been forgiven by God. This was a touching ending.

He left Paris with Haydee, and he found his ultimate happiness and fall in love with Haydee. Just as Li Dan said, The Count of Monte Cristo is one popular fiction which praise humanitarian. (Li Dan, 2008, p.84)[2]

\section{A Brief Introduction to Nirvana in Fire}

Nirvana in Fire revolved around a gifted young man named Lin Shu, whose father served as a general in the army. Already a high-ranking military officer by his teenager years, Lin Shu enjoyed a close friendship with Prince Xiao Jingyan and was even engaged to Princess Ni Huang. At age 17, Lin Shu's life turned upside down when his father's army was framed and obliterated by a scheming political rival. Thanks to his loyal soldiers, Lin Shu escaped death, but due to the cold environment, his body became weak and frail, and his face was permanently pale and his fingers always ice-cold. After 12 years, Lin Shu returned to his country's capital with a new name, Mei Changsu, and a new identity, the leader of the Jiang Zuo Alliance. He then became the strategic adviser for his friend, Prince Jingyan, who had been exiled by Jinghhuan and the crown prince to win the throne for them. Mei Changsu succeeded in paving the road for his friend to take over as king, as well as the avenging the injustices dealt to his troops many years before.

\section{SIMILARITIES IN REVENGE BETWEEN EDMOND AND MEI CHANGSU}

\section{A. The Plotting before Revenge}

For Edmond and Mei Changsu, in order to get their revenge on enemies, both of them have well planned the strategies.

In Nirvana in Fire, Lin Shu changed his name into Mei Changsu, and became the leader of Jiang Zuo Alliance with his intelligence. He prepared the plan for 12 years. Because of his identity and quality, he had a good relationship with people in every circle and all of them were loyal to him. At that time, Prince Xiao Jingheng and the crown prince were tried their best to win throne for themselves. They heard that Langya pavilion could answer all the questions in the world, so both of them wanted to get the tips of getting the throne. Undoubtedly, they got the same answer, only when they got the help of Mei Changsu, they could win. Therefore, the wrested for Mei Changsu. Of course this is his strategy. In this way, people would believe that Mei Changsu was forced to Jinling. In Jinling, he chose to be the strategic advisor for his friend; Prince Jingyan.Because Jingyan was straightforward and kindhearted. He planned everything for Jingyan. Before he came to Jinglin, he arranged lots of people of Jiang Zuo Alliance in Jinglin. Those people pretended to do different kinds of jobs so that they could get information and support Mei Changsu's strategy. Such as Miaoyin lane, which seemed to be a entertainment places, actually it was a place where Mei Changsu and uncle 13 got in touch.

In The Count of Monte Cristo, on the one hand, when Edmond got his freedom, he traveled to Monte Cristo and finds Faria's huge treasure. He came back to Marseilles. He got the details of the plot to frame him. He also knew the happy life of his enemies in Paris. What disappointed him most was that Mercedes had married Fernand Mondego. He lamented, "Frailty, the name is woman." (Dumas, 2010 p.278)[1].So in the next ten years, before he came to Rome, he gathered the damning knowledge about each of them. On the other hand, Edmond pretended to save Albert de Morcerf from bandits. In return for the favor, Albert introduced Edmond to Parisian society. Edmond was thus able to insinuate himself effortlessly into the lives of Danglars, Mondego, and Vicefort. And when Edmond came back to Marseiles, he learned that both Danglars and Mondego had become rich and powerful, and they were living happily in Paris. So ten years later, he came to Rome, calling himself the Count of Monte Cristo. Here Edmond set an elaborate scheme of revenge into motion.

\section{B. Others' Assistance in Revenge}

In order to exact revenge on their enemies, both Edmond and Mei Changsu had accepted others' help. In fact, the successful revenge was not only their achievements, but also other people's contributions.

In The Count of Monte Cristo, Edmond met Abble Fraia, an Italian priest and intellectual. Fraia taught Edmond history, science, philosophy and languages and turned him into a well-educated person. Fraia also bequeathed to Edmond a huge treasure hidden on the island, and he told Edmond how to find it. At first, they didn't trust each other, after Faria deduced the events surrounding Edmond imprisonment, Faria said," if you want to find the criminal, you should know who is the greatest beneficiary" (Dumas, 2010, p.154)[1]

We can see that Edmond couldn't get freedom without Fraia's help. Edmond also got help from Hydee, the daughter of Ali Pacha, the vizier of the Greek state of Yanina. Mendego was the first to be punished. Haydee testified against in front of the senate that Moncerf made his fortune by betraying Ali Pacha, and he sold Ali Pacha's wife and Haydee into slavery.So Monerf's good name was ruined and finally he committed suicide.

In Nirvana in Fire, the most typical example was Prince Jingrui, one of the friends of Mei Changsu, the son of Xie $\mathrm{Yu}$. They became sincere friends years ago in Langzhou and they kept in touch. Jingrui knew that Mei Changsu's body was weak. So he invited Mei Changsu to come Jinling to have recuperation. Naturally, Mei Changsu accepted this invitation. In this way, Mei Changsu could refuse king 
Jinghuan and crown prince's invitation and lived in Jingrui's home. At later time, Jingrui helped him a lot. Jingrui provided him the chance to know some key figures. And in Jingrui's birthday banquet, Mei Changsu defeated Xie Yu, one of the ringleaders in injustice. And general Meng also helped Mei Changsu a lot. In the past, he had stayed in chiyan army for one year. And he trusted that general Lin and 70000 soldiers were framed. So when Mei Changsu got in touch with him five years ago, he decided to help Lin Shu to revenge. Because of his high ranks, he provided Lin shu with lots of convenience, such as the house he chose for Lin Shu, which could secretly meet Prince Jingrui through a pass. The third typical person was Princess Ni Hong. She grew up with Lin Shu and she was engaged to him. After that war, she thought that she had lost Lin Shu forever. But when Lin Shu came back to Jinling to get his revenge, she recognized him and trusted him unconditionally. In lots of the strategies, she protected Lin Shu. She cared about Lin Shu and encouraged him to realize his goal. Moreover, she was willing to wait for Lin Shu until the revenge was accomplished.

\section{DIFFERENCES IN REVENGE BETWEEN EDMOND AND MEI CHANGSU}

\section{A. The Purposes of Revenge}

Even though Edmond and Mei Changsu were framed by others. The purposes of their revenge were different. For Edmond, he got the revenge for himself, and he wanted to ruin his enemies only. But for Mei Changsu, his revenge was not only for himself, but also for his family, his friends and 70000 soldiers. His ultimate purpose was to replace the corrupt government into a fair one.

Edmond was framed by three people. He considered his fortune a gift from God, given to him for the sole purpose of rewarding those who had tried to help him and more important, punishing those who had hurt him. So his purpose was to ruin these people. Morcerf committed suicide. Believing that everyone he loved was dead and knew that he would soon have to severe criminal charges. Villefort went insane and even Edmond spared Danglar's life but left him penniless.

In Nirvana in the Fire, Lin Shu and his family were framed by Xie $\mathrm{Yu}$. They involved in the injustice for keeping and getting more power, apart from this, they did lots of other cases unscrupulously to get high ranks. In the process of Mei Changsu's revenge, he overturned lots of conviction and defeated them is one of his purpose. At the same time, he paved the road for his friend to take over as king. Because he would be a good king with excellent qualities, so the second purpose of Mei Changsu's revenge is to turn the country into a fair and better one. So even though these two works elaborate the same thesis, because of the differences in cultures and other features, the differences between them are apparent. Just From the perspective of comparative literature, "every reading and understanding is a kind of historical activity done in a certain time and space, the differences in era and geographical features will lead to diversity of the awareness and understanding level, and this is how different explanation becomes." (Liu Xiangyu, 2010, p.33)[3]

\section{B. The Results of Revenge}

The results of Mei Changsu and Edmond were also different.

Mei Changsu's purpose of revenge was not only getting his revenge on Xie Yu. Mei Changsu avenged the injustice dealt to his troops many years before. He also wanted to make the nation fairer. So when the country faced the invasion of minority nationalities, Mei Changsu decided to follow the army to appease the conflicts. Even though he could only live three months, he wanted to devote his whole life to the country. Finally, Lin Shu lost his life in this war, but his friend Prince Jinghuan realized his desire that ruled the country in a fair way.

After Edmond ruined those three people, $\mathrm{He}$ also completed an act of goodness. He helped the brave Maximilian Morrel, the son of the kind captain, to be with Valentine Villefort forever. In the parting letter that Edmond left for Maximilian, he said "there is neither happiness nor misery in the world, there is only comparison of one state with another; nothing more." (Dumas, 2010, p.1273)[1]. He who has felt the deepest grief was best able to experience supreme happiness. Edmond suggested that only now that Maximilian had demonstrated a willingness to die in order to be reunited with Valentine could he truly appreciate living alongside her. Edmond spared Danglars' life. Because Danglars had shown apparent regret, Edmond was giving his enemy the chance to repent and been forgiven by God. Finally Edmond said, "All human wisdom is contained in these two words, wait and hope." (Dumas, 2010, p.1274)[1]. He thought that he finish God's desire, he left Paris with Haydee. He fallen in love with adoring Haydee and found his ultimate happiness.

\section{A FURTHER DISCUSSION UPON SIMILARITIES AND DIFFERENCES IN REVENGE}

\section{A. Factors behind the Similarities in Revenge}

Because of that revenge is an action of getting revenge on the people who had hurt their benefits and feelings. So the revenge in Chinese literature and Western shared some similarities. And the factors behind the similarities can be explained from three aspects. Firstly, both Mei Changsu and Edmond were framed by mean person, so these two revenges had the same motivation that punished their enemies and brought fair back to themselves. Secondly, revenge is a process which is full of difficulty. Both of their enemies became political, influential and wealthy people. So they had to prepare the revenge for many years. And the details they had to know very well. Finally, for revenge, a long and difficult process, individual efforts is insufficient. It was impossible for them to complete every detail. So others' assistance was necessary for the successful revenge. 


\section{B. Factors behind the Differences in Revenge}

1) Individualism VS Collectivism: Individualism is a kind of political and social philosophy, which emphasizes on individual freedom and self-control. As a philosophy, it contains one value system, theory of human nature, and the general attitude towards political, social, economic and religious behavior. The individualism originates in Renaissance and religious reform. Westerners value individual efforts, desire freedom and pursue their own benefits. Individualism is comprised of three aspects .firstly, belief in the primary importance of the individual and in the virtue of self-reliance and personal independence. Secondly, it is a doctrine of freedom from government regulation of personal economic or social goals. Thirdly, it is the doctrine that the interest of the individual should take precedence over the interest of the ground. All westerners believe that self-benefit above everything. Society is the means for them to realize individual goals. a society is made up of individual people, and individual person are the units of society.

While China has a long history, it has a totally different culture from western countries since primitive society. The clan society was well preserved by kinship. It is a social system where one should respect elder and care the young numbers. The core of this system is that people should give priority to family, family should give priority to clan society and clan society should give priority to the country and the whole nation. In general, society outweighs individuals. They believed that society is the most important, and groups are the units of society so that individual should submit to collectivism. Since ancient times, china follow the notion of great national unity, the history reveal that emperor intend to consolidate feudal society through this notion. As time goes by, this notion turned into collectivism.

In The Count of Monte Cristo, because individualism values their own benefits and efforts, so Edmond's three enemies, Danglars, Mondego and Villefort, framed him for their mean purposes. Danglars envied Edmond's early career success, and Mondego wanted to get Mercedes. For Villefort, he wanted to realize his ambitions regardless of Edmond's injustice. In the process of Edmond's revenge, he considered his fortune a gift from God, given to him for the sole purpose of rewarding those who had tried to help him and more important, punishing those who had hurt him. So the purpose of his revenge was to ruin his three enemies, everyone was pursuing money and money and they also ruined by these things. Edmond was just fought for his own benefits and this was a good explanation of Individualism. But for Mei Changsu, the purpose of revenge was not only to avenge the injustices dealt to his troops, but also to make the country better and fairer. He valued the social benefits and he believed that he was responsible for the prosperity of the country. The result seemed to be a reasonable ending. He devoted his life to the country and earned people's respect.

2) Extroversive VS Introversive: Since ancient Greek, the Westerns thinking with the nature is to practice object and the search and attention for the nature lead to the thinking mode of objectification. This mode of thinking points to the object apart from the subject. So the Westerns' mode of thinking is extroversive. Western culture has its root in the area of the Aegean Sea and Mediterranean in ancient Greek. Due to the special natural and geographical environment, the commercial economy, marine trade, open ideas is well developed. Since the ancient Greek, people had a very strong aggressive spirit, and this also caused Western's lively characteristics. Endowed with God-given rights, individuals value their own benefits and they will get every chance to show their uniqueness and without infringe the benefits of others are their basis of morality. The purpose of Westerners is in pursuit of benefits and in order to get their goals, they unscrupulous to do everything. In general, the Westerns are dynamic, brave, cooperative and aggressive.

Introversion is one feature of Chinese traditional thinking. Influenced by the harmony between the heaven and human, people got harmoniously with nature in China traditional culture. So the nature never is the opposite party of human, and there is no obvious opposite thinking. So the mode of Chinese thinking is introversive. The discrepancy of the climate and geographical environment caused the discrepancy of economic form and notion of society. China's continental geographic environment, small-scale and insufficiency lead to a lack of outside world, tunnel vision and thinking occlusion. People would seal off the outside world and superpower mentality would be easily produced. So the Chinese traditional thinking value self-help and the value originate in their own heart. The personality of stability and peace will make Chinese people settle for what they can get. China's moral idea regards human ethics and morality as center. They value the harmony among people and tolerant with authority. Moreover, they value loyalty over money and they always are cautious and tolerant.

In The Count of Monte Cristo, Edmond was a positive, smart and young man. He also had the quality to be a captain. After he was framed, he learned history, philosophy, and languages in prison and he tried his best to dig out from the prison. Without the spirit of adventure and courage, he couldn't complete this. His perseverance enabled him to find the enormous treasure and avenged successfully. While Mei Changsu valued justice higher than material gains. His father was framed by enemies. Therefore, the purpose of his revenge was not only for his father, but also for 70000 loyal soldiers. He regarded human ethics and morality the center.He was resigned and prudent.

\section{CONCLUSION}

Through a general expounding of revenge literature, The Count of Monte Cristo, and Nirvana in Fire, we have achieved recognition of revenge literature, as well as the similarities and differences between the two works. Because of that revenge is an action of punishing the people who had hurt their benefits and feelings. So the revenge of Mei Changsu and Edmond is identical to some extent. What make their revenge different is introversive VS extroversive and individualism VS collectivism. And the characteristics 
were rooted in different cultures. As for me, knowing the different characteristics of culture enables us to understand other cross-cultural issues better.

\section{REFERENCES}

[1] Dumas, The Count of Monte Cristo; Shanghai Translation Publishing House, 2010

[2] Li Dan, A brief Analysis of the Ideological Achievements of The Count of Monte Cristo; Heilongjiang Science and Technology Information, 2008

[3] Liu Xiangyu, An Introduction to Comparative Literature; Beijing Normal University Press, 2010.

[4] Adama, G. P. Knowledge and Society M New York. AppeltonCentury Company, 1938.

[5] Binoy Jiban Ghosh.The Revolt of 1905 in Bengal. Calcutta, 1987.

[6] Cole, M. Scrioner S. Culture and Thought; A psychological Introduction. New York John Wiley\&sons, 1974

[7] Kaplen, Robert. Cultural Thought Patterns in Intercultural Education. Language learning, 1966.

[8] R. C. Majumdar, The Struggle for Freedom M Bombay. 1963.

[9] Richard Paul Cromin. The English Government and Advertise in Bengal(1905-1912).Caleuta, 1977. 